\title{
Lactococcus lactis subsp. tructae subsp. nov. isolated from the intestinal mucus of brown trout (Salmo trutta) and rainbow trout (Oncorhynchus mykiss)
}

\author{
Tania Pérez, ${ }^{1}$ José Luis Balcázar, ${ }^{2}$ Alvaro Peix, ${ }^{3}$ Angel Valverde, ${ }^{3}$ \\ Encarna Velázquez, ${ }^{4}$ Ignacio de Blas ${ }^{1}$ and Imanol Ruiz-Zarzuela ${ }^{1}$ \\ ${ }^{1}$ Laboratory of Fish Pathology, Faculty of Veterinary Sciences, Universidad de Zaragoza, 50013 \\ Zaragoza, Spain \\ ${ }^{2}$ Catalan Institute for Water Research (ICRA), Scientific and Technological Park of the University of \\ Girona, 17003 Girona, Spain \\ ${ }^{3}$ Instituto de Recursos Naturales y Agrobiología de Salamanca - Consejo Superior de \\ Investigaciones Científicas (IRNASA-CSIC), Salamanca, Spain \\ ${ }^{4}$ Departamento de Microbiología y Genética, Universidad de Salamanca, Salamanca, Spain
}

Correspondence Encarna Velázquez evp@gugu.usal.es

\begin{abstract}
The species Lactococcus lactis currently includes three subspecies; $L$. lactis subsp. lactis and $L$. lactis subsp. cremoris, isolated from milk sources, and L. lactis subsp. hordniae, isolated from the leafhopper Hordnia circellata. In this study, three strains, designated L105 ${ }^{\top}, \mathrm{I} 3$ and L101, were isolated from the intestinal mucus of brown trout (Salmo trutta) and rainbow trout (Oncorhynchus mykiss). These strains were closely related to members of the species Lactococcus lactis. Strain $\mathrm{L} 105^{\top}$ showed $99.4 \% 16 \mathrm{~S}$ rRNA gene sequence similarity to that of the type strains L. lactis subsp. lactis NCDO $604^{\top}$ and L. lactis subsp. hordniae NCDO $2181^{\top}$ and showed $99.9 \%$ similarity to the type strain Lactococcus lactis subsp. cremoris NCDO $607^{\top}$. Analysis of two housekeeping genes, $r p o B$ and $r e c A$, confirmed the close relationship between the novel strains and $L$. lactis subsp. cremoris with similarities of 99.3 and $99.7 \%$, respectively. The three strains could, however, be differentiated from their closest relatives on the basis of several phenotypic characteristics, as was the case for $L$. lactis subsp. lactis and L. lactis subsp. hordniae, which were also closely related on the basis of $16 \mathrm{~S}$ rRNA, rpo $B$ and $\operatorname{rec} A$ gene sequence similarities. The strains isolated in this study represent a new subspecies, for which the name Lactococcus

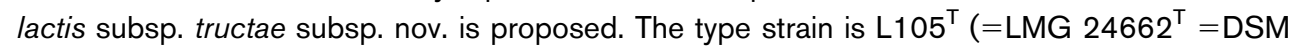
$\left.21502^{\top}\right)$.
\end{abstract}

The genus Lactococcus currently contains six species isolated from different vegetal, animal and food sources, with $L$. piscium as the only species hitherto isolated from salmonid fish (Williams et al., 1990). Within the species Lactococcus lactis (Schleifer et al., 1985), three subspecies are currently recognized; L. lactis subsp. lactis and L. lactis subsp. cremoris, isolated from milk sources, and L. lactis subsp. hordniae, isolated from the leafhopper Hordnia

Abbreviations: RAPD, random amplification of polymorphic DNA; REP, repetitive sequence-based.

The GenBank/EMBL/DDBJ accession numbers for the 16S rRNA, rpo $B$ and recA gene sequences of strain $\mathrm{L}_{105^{\top}}$ are EU770697, GU799692 and GU799681, respectively.

Three supplementary figures and two supplementary tables are available with the online version of this paper. circellata (Latorre-Guzmán et al., 1977). Recently, strains of $L$. lactis subsp. lactis have been also isolated from the intestinal tracts of freshwater fish (Itoi et al., 2008, 2009).

In this study, three novel strains, designated $\mathrm{L} 105^{\mathrm{T}}$, I3 and L101, were isolated from two different salmonid species, brown trout (Salmo trutta) and rainbow trout (Oncorhynchus mykiss). Phylogenetic analyses based on $16 \mathrm{~S}$ rRNA, rpoB and recA gene sequences placed these strains within the species Lactococcus lactis but their phenotypic characteristics were different to those of the three subspecies currently recognized in the species. Based on this evidence strain $\mathrm{L} 105^{\mathrm{T}}$ represents the type strain of a new subspecies within Lactococcus lactis, for which the name Lactococcus lactis subsp. tructae subsp. nov. is proposed. 
The three novel strains were isolated from the intestinal mucus of salmonid fish by growth on Man-Rogosa-Sharpe agar (MRS; Pronadisa, Madrid, Spain) at $22{ }^{\circ} \mathrm{C}$ for $24 \mathrm{~h}$. Strain $\mathrm{L}_{105^{\mathrm{T}}}$ was isolated from brown trout and strains L101 and I3 were isolated from rainbow trout. Colonies were white-cream, opaque, round and convex.

The Gram reaction was ascertained by using standard staining methods (Doetsch, 1981). Cells of the three isolates were Gram-reaction-positive, non-sporulating, non-motile cocci, similar to members of other subspecies of Lactococcus lactis.

Amplification and sequencing of the 16S rRNA gene was performed as described by Rivas et al. (2007). The sequences obtained were compared with closely related sequences obtained from GenBank using the BLASTN program (Altschul et al., 1990) and aligned using the CLUSTAL W software (Thompson et al., 1997). Distances were calculated according to Kimura's two-parameter model (Kimura, 1980). Phylogenetic trees were reconstructed using the neighbour-joining method (Saitou \& Nei, 1987), with bootstrap analysis based on 1000 resamplings. The MEGA 4.0 package (Tamura et al., 2007) was used for all analyses.

The 16S rRNA gene sequences of the three strains isolated in this study were identical and thus only that of the type strain was analysed and deposited in GenBank. Comparison of complete 16S rRNA gene sequences (1541 bp) with those held in the GenBank database indicated that strain $\mathrm{L}_{105^{\mathrm{T}}}$ belonged to the species Lactococcus lactis, showing $99.4 \%$ sequence similarity to the type strains L. lactis subsp. lactis $\mathrm{NCDO} 604^{\mathrm{T}}$ and L. lactis subsp. hordniae $\mathrm{NCDO} 2181^{\mathrm{T}}$ and $99.9 \%$ similarity to the type strain L. lactis subsp. cremoris $\mathrm{NCDO} 607^{\mathrm{T}}$. In agreement with these results, strain $\mathrm{L} 105^{\mathrm{T}}$ clustered with L. lactis subsp. cremoris NCDO $607^{\mathrm{T}}$ in the phylogenetic tree (Fig. 1). In this analysis, two strains isolated from fish by Itoi et al. (2009) were included (Supplementary Fig. S1, available in IJSEM Online) showing that they also clustered with L. lactis subsp. lactis and L. lactis subsp. hordniae.

Repetitive sequence-based (REP)-PCR pattern analysis using primer $(\mathrm{GTG})_{5}$ has previously been shown to be an effective tool for the differentiation of L. lactis subspecies (Rademaker et al., 2007; Svec \& Sedlácek, 2008). Therefore, we analysed REP-PCR patterns of the novel isolates and the reference strains of each subspecies of $L$. lactis
(Supplementary Fig. S2), according to the methodology described by Marilley et al. (2004). The results showed that strains belonging to the same subspecies displayed the same REP-PCR pattern and that patterns were clearly different among members of different subspecies of L. lactis. Our results confirmed that REP-PCR fingerprinting is a rapid and reliable technique for the differentiation of subspecies within the species L. lactis. In order to analyse the genetic diversity of the three strains isolated in this study, random amplification of polymorphic DNA (RAPD) analysis was performed using the primer M13 (5'-GAGGGTGGCGGTTCT-3'), according to Rivas et al. (2006). The results showed that the patterns of strains $\mathrm{L}_{105^{\mathrm{T}}}, \mathrm{L} 101$ and I3 (lanes 7, 8 and 9, respectively; Supplementary Fig. S3) were different. These patterns were also different to those of the type strains of the three recognized subspecies of L. lactis (Supplementary Fig. S3, lanes 1, 3 and 5). The results of the RAPD analysis showed that the three novel strains isolated in this study were genotypically diverse, despite their $16 \mathrm{~S}$ rRNA gene sequence similarities.

The usefulness of housekeeping genes in bacterial taxonomy and phylogeny has been reported for several bacterial groups (Maiden, 2006) including Gram-positive cocci of the genus Streptococcus, a genus that is phylogenetically close to Lactococcus (Glazunova et al., 2009; Pombert et al., 2009). In this study, the partial sequences of two housekeeping genes, $r p o B$ ( $460 \mathrm{nt})$ and recA ( $\sim 330 \mathrm{nt})$, were obtained from type strains of species of genus Lactococcus and from the strains isolated in this study. Gene amplification and sequencing were performed using the primers rpoBLac1F (5'-TACGGKAAACACCGTA-3'), rpoBLac1R (5' ${ }^{\prime}$ TCAARCCAWGCTCCACGG$\left.3^{\prime}\right)$, recALac1F (5'-GCAGCCTTTATCGATGCTG-3') and recAlR (5'-GCACGACCACCAGG-3'), which were designed on the basis of conserved regions of these genes in strains L. lactis subsp. lactis KF147 (accession no. CP001834) and L. lactis subsp. cremoris SK11 (accession no. CP000425). The PCR conditions were as follows: preheating at $95{ }^{\circ} \mathrm{C}$ for $9 \mathrm{~min}$, followed by 35 cycles of denaturing at $95{ }^{\circ} \mathrm{C}$ for $1 \mathrm{~min}$, annealing at $52{ }^{\circ} \mathrm{C}(\mathrm{rec} A)$ or at $47.5{ }^{\circ} \mathrm{C}(r p o B)$ for $1 \mathrm{~min}$ and extension at $72{ }^{\circ} \mathrm{C}$ for $1 \mathrm{~min}$, and a final extension at $72{ }^{\circ} \mathrm{C}$ for $7 \mathrm{~min}$. Results of the phylogenetic analysis of $r p o B$ and $r e c A$ gene sequences are shown in Figs 2 and 3, respectively. Since this was, to our knowledge, the first study of the $r p o B$ and $r e c A$ genes in species of genus Lactococcus, there were no previous data relating to similarity levels in these genes among strains of the same species or among different species of the genus.

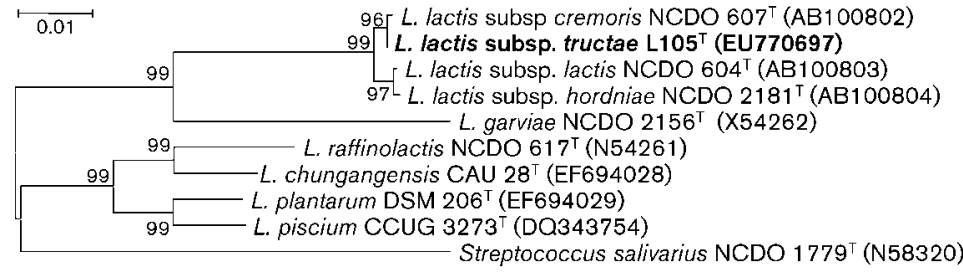

Fig. 1. Neighbour-joining tree based on $16 \mathrm{~S}$ rRNA gene sequences of strains $L 105^{\top}$, I3 and $\mathrm{L} 101$ and other related taxa. Bootstrap values $>50 \%$, based on 1000 subsets, are given at branch points. Bar, 0.01 substitutions per nucleotide position. 


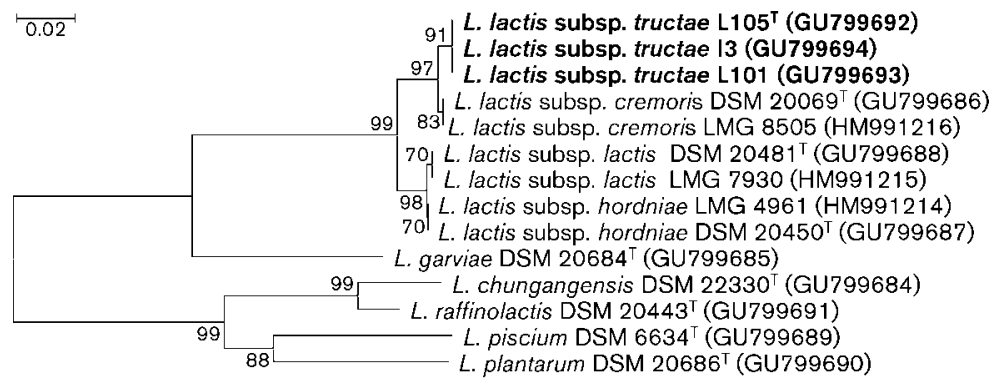

Fig. 2. Neighbour-joining tree based on partial rpoB gene sequences of strains $L 105^{\top}, \mathrm{I} 3$ and $\mathrm{L} 101$ and other related taxa. Bootstrap values $>50 \%$, based on 1000 subsets, are given at branch points. Bar, 0.02 substitutions per nucleotide position.
Nevertheless, results of analyses on members of the genus Streptococcus, belonging to the same family as Lactococcus, showed that two closely related species, $S$. salivarius and $S$. vestibularis, showed $r p o B$ and recA gene sequence similarities of 97 and $91 \%$, respectively, to one another (Drancourt et al., 2004; Glazunova et al., 2009; Pombert et al., 2009). Results obtained between members of different species of the genus Lactococcus showed lower similarity values (up to $30 \%$ divergence) in both genes (Figs 2 and 3). These results showed that the $r p o B$ and $r e c A$ genes could be highly useful for species differentiation within the genus Lactococcus. Moreover, these results showed that the type strains of L. lactis subsp. cremoris and L. lactis subsp. lactis had $r p o B$ and $r e c A$ gene sequence similarities ( 97.2 and $91.8 \%$, respectively) that were at the limit for species differentiation, as was the case for members of the genus Streptococcus. The type strain of $L$. lactis subsp. hordniae was more closely related to L. lactis subsp. lactis, with $\sim 99.8 \%$ sequence similarity in both genes (representing one nucleotide difference, in both cases, in the fragment analysed), than to L. lactis subsp. cremoris, with which it showed $r p o B$ and $r e c A$ gene sequence similarities of $\sim 97.3$ and $92 \%$, respectively. As a group, the three novel strains had an internal similarity level of $100 \%$ in these two genes and, as in the case of the $16 S$ rRNA gene sequence analysis, formed a cluster with $L$. lactis subsp. cremoris after the phylogenetic analysis of $r p o B$ and $\operatorname{rec} A$ gene sequences (Figs 2 and 3 ). The sequence similarity values with respect to this subspecies were $99.3 \%$ $(r p o B)$ (indicating a difference of three nucleotides in the fragment analysed) and $99.7 \%(\mathrm{rec} A)$ (difference of one nucleotide in the fragment analysed). These data suggested that the three isolates represent a novel subspecies within the species L. lactis.
The DNA G + C content of strain $\mathrm{L} 105^{\mathrm{T}}$ was determined by the DSMZ Identification Service. For base composition analysis, DNA was extracted and purified according to Cashion et al. (1977). The DNA was hydrolysed with P1 nuclease and the nucleotides were dephosphorylated with bovine alkaline phosphatase (Mesbah et al., 1989). The DNA G $+C$ content of strain $\mathrm{L}_{105^{\mathrm{T}}}$ was $36.0 \mathrm{~mol} \%$, as determined by HPLC according to Mesbah et al. (1989) using a Shimadzu HPLC system. DNA-DNA hybridization analyses were performed according to the method of Ezaki et al. (1989), following the recommendations of Willems et al. (2001). DNA relatedness values between strain $\mathrm{L} 105^{\mathrm{T}}$ and the type strains of L. lactis subsp. lactis, L. lactis subsp. cremoris and L. lactis subsp. hordniae were 62, 90 and $60 \%$, respectively. These values were in agreement with the results of the $16 \mathrm{~S}$ rRNA, $r p o B$ and $r e c A$ gene sequence analyses, showing that the three novel strains were more closely related to L. lactis subsp. cremoris than to L. lactis subsp. lactis and L. lactis subsp. hordniae.

Cellular fatty acids were analysed by the DSMZ Identification Service, according to the instructions of the Microbial Identification System (MIDI). The fatty acid profile of strain L $105^{\mathrm{T}}$ was similar to that of L. lactis according to the data recorded in the MIDI database, which was in agreement with the results of $16 \mathrm{~S}$ rRNA gene sequence analysis. The major fatty acids detected in strain $\mathrm{L}_{105^{\mathrm{T}}}$ were $\mathrm{C}_{16: 0}(37.6 \%)$ and $\mathrm{C}_{19: 0}$ cyclo $\omega 8 c(26.6 \%)$; other fatty acids detected included $\mathrm{C}_{14: 0}(13.1 \%), \mathrm{C}_{18: 1} \omega 7 c(14.4 \%), \mathrm{C}_{18: 0}(1.0 \%), \mathrm{C}_{20: 2} \omega 6,9 c$ $(1.0 \%), 11$ methyl $\mathrm{C}_{18: 1} \omega 7 c(1.5 \%)$ and summed feature 3 $\left(\mathrm{C}_{16: 1} \omega 7 c /\right.$ iso- $\left.\mathrm{C}_{15: 0} 2-\mathrm{OH}\right)(4.3 \%)$. This profile is closest in composition to that of $L$. lactis subsp. cremoris than to those of L. lactis subsp. lactis or L. lactis subsp. hordniae although there were slight differences in the amounts of various fatty acids (Supplementary Table S1).

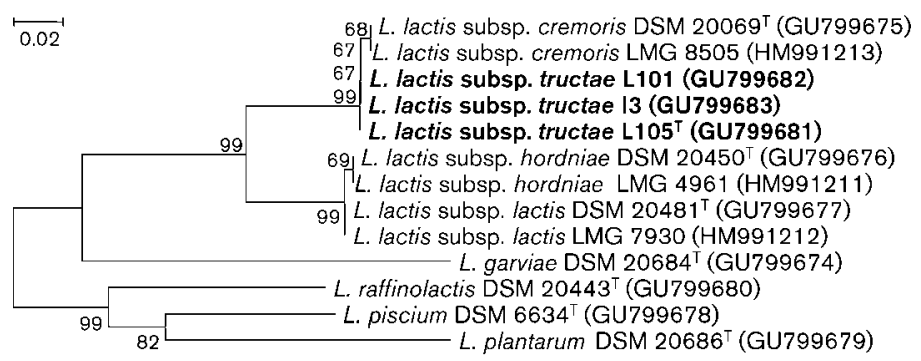

Fig. 3. Neighbour-joining tree based on partial rec $A$ gene sequences of strains $L 105^{\top}, 13$ and $\mathrm{L} 101$ and other related taxa. Bootstrap values $>50 \%$, based on 1000 subsets, are given at branch points. Bar, 0.02 substitutions per nucleotide position. 
Table 1. Characteristics of strains $L 105^{\top}, I 3$ and $L 101$ and other related taxa of the genus Lactococcus

Taxa: 1, L105 ${ }^{\mathrm{T}}$; 2, I3; 3, L101; 4, L. lactis subsp. lactis (DSM 20481 ${ }^{\mathrm{T}}$ and LMG 7930); 5, L. lactis subsp. hordniae (DSM 20450 ${ }^{\mathrm{T}}$ and LMG 9462); 6, L. lactis subsp. cremoris (DSM $20069^{\mathrm{T}}$ and LMG 8505); 7, L. chungangensis CAU $28^{\mathrm{T}} ; 8$, L. garvieae KCTC $3772^{\mathrm{T}}$; 9, L. pisicium DSM 6634 ${ }^{\mathrm{T}}$ (results from Williams et al., 1990; Teuber, 2009); 10, L. plantarum DSM $20686^{\mathrm{T}}$; 11, L. raffinolactis DSM $20443^{\mathrm{T}}$. Results for 1-3 and all antibiotic sensitivity tests are from this study. Other results obtained in this study agree with those of Teuber (2009) for taxa 4-6 and 8-11, Schleifer et al. (1985) for taxa 4, 5, 6, 8, 10 and 11 and Cho et al. (2008) for species 7. +, Positive; -, negative; v, variable; w, weak; ND, no data; S, sensitive; $\mathrm{R}$, resistant; $\mathrm{w}$, weakly resistant.

\begin{tabular}{|c|c|c|c|c|c|c|c|c|c|c|c|}
\hline Characteristic & 1 & 2 & 3 & 4 & 5 & 6 & 7 & 8 & 9 & 10 & 11 \\
\hline Growth in $4 \%(\mathrm{w} / \mathrm{v}) \mathrm{NaCl}$ & + & + & + & + & - & - & - & + & - & + & - \\
\hline Production of arginine dihydrolase ${ }^{\star}$ & + & + & + & + & + & - & - & + & - & - & - \\
\hline \multicolumn{12}{|l|}{ Acid from ${ }^{\dagger}$ : } \\
\hline Ribose $^{*}$ & + & + & + & + & - & - & $\mathrm{ND}$ & + & - & - & $\mathrm{V}$ \\
\hline D-Xylose & - & - & - & + & - & $-\ddagger$ & - & - & + & - & $\mathrm{V}$ \\
\hline Mannitol $^{*}$ & + & + & + & $\mathrm{v}$ & - & - & + & - & + & + & - \\
\hline Lactose $^{*}$ & + & + & + & $\mathrm{V}$ & - & + & - & + & + & - & + \\
\hline Maltose & + & + & + & + & - & - & + & + & + & + & + \\
\hline Melibiose & + & + & - & - & - & - & - & - & + & - & + \\
\hline Sucrose & + & + & + & $\mathrm{V}$ & + & - & + & - & + & + & + \\
\hline Raffinose $^{*}$ & + & + & - & - & - & - & - & - & + & - & + \\
\hline Amygdalin* & + & + & + & $\mathrm{w}$ & - & - & + & + & + & + & - \\
\hline Assimilation of gluconate ${ }^{\dagger}$ & + & + & + & - & - & - & ND & ND & $\mathrm{ND}$ & - & - \\
\hline \multicolumn{12}{|l|}{ Resistance/sensitivity to: } \\
\hline Cefuroxime & s & s & s & $\mathrm{R}$ & s & S & $\mathrm{s}$ & s & s & s & $\mathrm{s}$ \\
\hline Tetracycline & s & s & $\mathrm{R}$ & S & $\mathrm{V}$ & $\mathrm{w}$ & S & s & s & s & s \\
\hline Erythromycin & $\mathrm{R}$ & $\mathrm{R}$ & $\mathrm{R}$ & s & s & s & $\mathrm{R}$ & $\mathrm{R}$ & s & s & s \\
\hline Polymyxin B & $\mathrm{R}$ & $\mathrm{R}$ & $\mathrm{R}$ & $\mathrm{R}$ & s & s & $\mathrm{w}$ & $\mathrm{R}$ & $\mathrm{R}$ & $\mathrm{R}$ & $\mathrm{w}$ \\
\hline
\end{tabular}

${ }^{*}$ After $24 \mathrm{~h}$ of incubation in API 20 STREP.

$\dagger$ After $24 \mathrm{~h}$ of incubation in API $50 \mathrm{CH}$.

$\ddagger$ Results were positive for strain KCCM $40699^{\mathrm{T}}$ (Cho et al., 2008).

Acid production from carbohydrates was tested using the API 20 STREP and API $50 \mathrm{CH}$ systems according to the manufacturer's instructions. The results were interpreted following the method of Schleifer et al. (1985). Growth in presence of $4 \% \mathrm{NaCl}$ was determined using TSA (Difco) as basal medium. For testing antibiotic resistance, the disc diffusion method on sheep blood agar plates (Scharlau Microbiology) was used with the following antibiotics $(\mu \mathrm{g}$ per disc, unless otherwise stated): ampicillin (2), erythromycin (2), ciprofloxacin (5), penicillin (10 IU), polymyxin (300 IU), cloxacillin (1), oxytetracycline (30), gentamicin (10), cefuroxime (30) and neomycin (5) (Becton Dikinson). The type strains of the three subspecies of L. lactis and the reference strains used in REP-PCR and RAPD analyses were included in the phenotypic study. Several differences were noted between the three novel isolates and representatives of the three recognized subspecies of L. lactis (Table 1). Complete results of the antibiotic resistance tests are given in Supplementary Table S2. Biocoding from the API 20 STREP tests gave a result of 7203551 for strains $L 105^{\mathrm{T}}$ and $\mathrm{I} 3$ and 7203511 for strain L101. The two codes matched with $L$. lactis subsp. lactis at $39 \%$ and $87.8 \%$, respectively, in the API AB database. The results of the phenotypic characterization showed that, despite high levels of $16 \mathrm{~S}$ rRNA, rpoB and $\operatorname{rec} A$ gene sequence similarity between the three novel strains and reference strains of the other subspecies, the strains were phenotypically diverse and varied in their ability to produce acid from several carbon sources as well as in their natural resistance to certain antibiotics. These strains differed from the remaining members of subspecies of $L$. lactis in several characteristics, as can be seen in Table 1.

Our results confirmed that the subspecies L. lactis subsp. hordniae and L. lactis subsp. lactis, despite being closely related based on the genes analysed in this study, possess phenotypic differences that are sufficient to differentiate between members of L. lactis at the subspecies level, as reported by Schleifer et al. (1985). Similarly, the novel isolates presented many phenotypic differences from their closest phylogenetic relative L. lactis subsp. cremoris that distinguish them as two separate subspecies. The remaining subspecies could be clearly differentiated on the basis of 16S rRNA and housekeeping gene sequence analyses and all subspecies of L. lactis could be differentiated by REP-PCR fingerprinting. Based on the evidence presented in this study, strains $\mathrm{L} 105^{\mathrm{T}}$, I3 and $\mathrm{L} 101$ represent a novel subspecies of Lactococcus lactis, for which the name Lactococcus lactis subsp. tructae subsp. nov. is proposed. 


\section{Description of Lactococcus lactis subsp. tructae subsp. nov.}

Lactococcus lactis subsp. tructae (truc'ta.e L. gen. n. tructae of a trout fish).

Characteristics additional to those reported in the original description of the species Lactococcus lactis (Schleifer et al., 1985) that allow the differentiation of the novel strains from the remaining subspecies of this species are given below.

Arginine dehydrolase production is positive after $24 \mathrm{~h}$ of incubation. Grows in $4 \% \mathrm{NaCl}$. Positive for assimilation of gluconate. Acid is produced from maltose, lactose, ribose, mannitol, sucrose and amygdalin but not from D-xylose. Acid production from melibiose and raffinose is variable. Sensitive to cefuroxime and resistant to erythromycin and polymyxin B. Resistance to tetracyclin is variable.

The type strain, $\mathrm{L}_{105^{\mathrm{T}}}\left(=\mathrm{LMG} 24662^{\mathrm{T}}=\mathrm{DSM} 21502^{\mathrm{T}}\right.$ ), was isolated from the intestinal mucus of brown trout (Salmo trutta). The DNA G $+\mathrm{C}$ content of the type strain of the subspecies is $36.0 \mathrm{~mol} \%$.

\section{Acknowledgements}

This work was supported by grants from the Spanish Government awarded to E.V.P. and by a fellowship from the Government of Aragón awarded to T.P.

\section{References}

Altschul, S. F., Gish, W., Miller, W., Myers, E. W. \& Lipman, D. J. (1990). Basic local alignment search tool. J Mol Biol 215, 403-410.

Cashion, P., Holder-Franklin, M. A., McCully, J. \& Franklin, M. (1977). A rapid method for the base ratio determination of bacterial DNA. Anal Biochem 81, 461-466.

Cho, S. L., Nam, S. W., Yoon, J. H., Lee, J. S., Sukhoom, A. \& Kim, W. (2008). Lactococcus chungangensis sp. nov., a lactic acid bacterium isolated from activated sludge foam. Int J Syst Evol Microbiol 58, 1844-1849.

Doetsch, R. N. (1981). Determinative Methods of Light Microscopy. In Manual of Methods for General Bacteriology, pp. 21-33. Edited by P. Gerdhardt, R. G. E. Murray, R. N. Costilow, E. W. Nester, W. A. Wood, N. R. Krieg \& G. B. Phillips. Washington: American Society for Microbiology.

Drancourt, M., Roux, V., Fournier, P.-E. \& Raoult, D. (2004). rpoB gene sequence-based identification of aerobic Gram-positive cocci of the genera Streptococcus, Enterococcus, Gemella, Abiotrophia, and Granulicatella. J Clin Microbiol 42, 497-504.

Ezaki, T., Hashimoto, Y. \& Yabuuchi, E. (1989). Fluorometric deoxyribonucleic acid-deoxyribonucleic acid hybridization in microdilution wells as an alternative to membrane filter hybridization in which radioisotopes are used to determine genetic relatedness among bacterial strains. Int J Syst Bacteriol 39, 224-229.

Glazunova, O. O., Raoult, D. \& Roux, V. (2009). Partial sequence comparison of the $r p o B$, sodA, groEL and $\operatorname{gyr} B$ genes within the genus Streptococcus. Int J Syst Evol Microbiol 59, 2317-2322.

Itoi, S., Abe, T., Washio, S., Ikuno, E., Kanomata, Y. \& Sugita, H. (2008). Isolation of halotolerant Lactococcus lactis subsp. lactis from intestinal tract of coastal fish. Int J Food Microbiol 121, 116-121.
Itoi, S., Yuasa, K., Washio, S., Abe, T., Ikuno, E. \& Sugita, H. (2009). Phenotypic variation in Lactococcus lactis subsp. lactis isolates derived from intestinal tracts of marine and freshwater fish. J Appl Microbiol 107, 867-874.

Kimura, M. (1980). A simple method for estimating evolutionary rates of base substitutions through comparative studies of nucleotide sequences. J Mol Evol 16, 111-120.

Latorre-Guzmán, B. A., Kado, C. I. \& Kunkee, R. (1977). Lactobacillus hordniae, a new species from the leafhopper (Hordnia circellata). Int $\mathrm{J}$ Syst Bacteriol 27, 362-370.

Maiden, M. C. (2006). Multilocus sequence typing of bacteria. Annu Rev Microbiol 60, 561-588.

Marilley, L., Ampuero, S., Zesiger, T. \& Casey, M. G. (2004). Screening of aroma-producing lactic acid bacteria with an electronic nose. Int Dairy J 14, 849-856.

Mesbah, M., Premachandran, U. \& Whitman, W. B. (1989). Precise measurement of the $\mathrm{G}+\mathrm{C}$ content of deoxyribonucleic acid by highperformance liquid chromatography. Int J Syst Bacteriol 39, 159-167.

Pombert, J.-F., Sistek, V., Boissinot, M. \& Frenette, M. (2009). Evolutionary relationships among salivarius streptococci as inferred from multilocus phylogenies based on $16 \mathrm{~S}$ rRNA-encoding, recA, $\sec A$, and $\sec Y$ gene sequences. BMC Microbiol 9, 232.

Rademaker, J. L., Herbet, H., Starrenburg, M. J., Naser, S. M., Gevers, D., Kelly, W. J., Hugenholtz, J., Swings, J. \& van Hylckama Vlieg, J. E. (2007). Diversity analysis of dairy and nondairy Lactococcus lactis isolates, using a novel multilocus sequence analysis scheme and (GTG)5-PCR fingerprinting. Appl Environ Microbiol 73, 7128-7137.

Rivas, R., Peix, A., Mateos, P. F., Trujillo, M. E., Martínez-Molina, E. \& Velázquez, E. (2006). Biodiversity of populations of phosphate solubilizing rhizobia that nodulate chickpea in different Spanish soils. Plant Soil 287, 23-33.

Rivas, R., Garcia-Fraile, P., Mateos, P. F., Martínez-Molina, E. \& Velázquez, E. (2007). Characterization of xylanolytic bacteria present in the bract phyllosphere of the date palm Phoenix dactylifera. Lett Appl Microbiol 44, 181-187.

Saitou, N. \& Nei, M. (1987). The neighbor-joining method: a new method for reconstructing phylogenetic trees. Mol Biol Evol 4, 406425.

Schleifer, K. H., Kraus, J., Dvorak, C., Klipper-Balz, R., Collins, M. D. \& Fischer, W. (1985). Transfer of Streptococcus lactis and related streptococci to the genus Lactococcus gen. nov. Syst Appl Microbiol 6, 183-195.

Svec, P. \& Sedlácek, I. (2008). Characterization of Lactococcus lactis subsp. lactis isolated from surface waters. Folia Microbiol (Praha) 53, 53-56.

Tamura, K., Dudley, J., Nei, M. \& Kumar, S. (2007). MEGA4: molecular evolutionary genetics analysis (MEGA) software version 4.0. Mol Biol Evol 24, 1596-1599.

Teuber, M. (2009). Genus II. Lactococcus Schleifer, Kraus, Dvorak, Kilpper-Bäiz, Collins and Fisher 1986, 354 $\mathrm{VP}$. In Bergey's Manual of Systematic Bacteriology, 2nd edn, vol. 3, pp. 711-722. Edited by P. de Vos, G. M. Garrity, D. Jones, N. R. Krieg, W. Ludwig, F. A. Rainey, K. H. Schleifer \& W. B. Whitman. New York: Springer.

Thompson, J. D., Gibson, T. J., Plewniak, F., Jeanmougin, F. \& Higgins, D. G. (1997). The CLUSTAL_X windows interface: flexible strategies for multiple sequence alignment aided by quality analysis tools. Nucleic Acids Res 25, 4876-4882.

Willems, A., Doignon-Bourcier, F., Goris, J., Coopman, R., de Lajudie, P., De Vos, P. \& Gillis, M. (2001). DNA-DNA hybridization study of Bradyrhizobium strains. Int J Syst Evol Microbiol 51, 1315-1322.

Williams, A. M., Fryer, J. L. \& Collins, M. D. (1990). Lactococcus piscium sp. nov. a new Lactococcus species from salmonid fish. FEMS Microbiol Lett 68, 109-113. 